\title{
Higher occurrence of asthma-related symptoms in an urban than a suburban area in adults, but not in children
}

\author{
M.H. Wieringa*, P.A. Vermeire", H.P. Van Bever", V.J. Nelen ${ }^{+}$, J.J. Weyler ${ }^{+}$
}

\begin{abstract}
Higher occurrence of asthma-related symptoms in an urban than a suburban area in adults, but not in children. M.H. Wieringa, P.A. Vermeire, H.P. Van Bever, V.J. Nelen, J.J. Weyler. C) ERS Journals Ltd 2001.

ABSTRACT: In young adults, a higher occurrence of asthma-related symptoms was found in an urban than an adjacent suburban area in a survey performed in 1991. The authors now wondered whether such differences could be established in other age groups.

The present study (in 1996) included 14,299 subjects, aged 5-75 yrs, of a random sample of the general population in the same two adjacent areas: the centre of Antwerp (Belgium) and its south suburban border. The standardized European Community Respiratory Health Survey (ECRHS) and International Study of Asthma and Allergies in Childhood (ISAAC) questionnaires were used to assess the occurrence of asthmarelated symptoms.

Higher rates were confirmed in urban compared to suburban Antwerp in adults (20-75 yrs), but no such area differences were found in children (5-8 and 12-15 yrs). Adjustment for a number of recorded risk factors did not seem to affect the area differences in asthma-related symptoms. Comparing the survey results of 1991 and 1996 in 20-44 yr old adults, the findings suggest a slight increase in reported respiratory symptoms in both areas.

A higher occurrence of asthma symptoms was observed in the urban than suburban area in adults, but not in children. This might be explained by a progressive effect of long-term exposure to the "urban environment". However, longitudinal studies are necessary to further clarify the factors accounting for these age-related area differences. Eur Respir J 2001; 17: 422-427.
\end{abstract}

The prevalence of respiratory symptoms and asthma is increasing worldwide, especially in westernized countries. It therefore remains important to identify risk factors responsible for this increase. Studies comparing asthma prevalence in different countries and regions, such as the European Community Respiratory Health Survey (ECRHS) [1] in adults and the International Study of Asthma and Allergies in Childhood (ISAAC) [2], have identified large differences between countries. Higher prevalence rates of asthma and allergic disorders found in children [3] and adults [4] in cities in West compared to East Germany, have led to the suggestion that increasing prevalence is associated with a Western lifestyle. In Belgium, differences in occurrence of respiratory symptoms have recently been reported between young adults in an urban and suburban area [5, 6], that were of a similar magnitude to those found in the same age group between Hamburg and the formerly East-German city of Erfuhrt [4].

This study further investigated these urban-suburban differences in respiratory symptoms by repeating the survey in young adults and by extending it to other age groups. It was considered whether these differences would be age-related and reproducible, in a homogeneous Flemish population of subjects with an age range 5-75 yrs, living in a small geographical area.
*Depts of Epidemiology and Community Medicine, ${ }^{\#}$ Respiratory Medicine and Pediatrics of the University of Antwerp (UIA) and ${ }^{+}$Provincial Institute of Hygiene, Antwerp, Belgium.

Correspondence: P.A. Vermeire, Dept. Respiratory Medicine, University of Antwerp (UIA), Universiteitsplein 1, B-2610, Antwerp, Belgium. Fax: 3238202590

Keywords: Adults, asthma, children, elderly, epidemiology, urban-suburban

Received: January 272000

Accepted after revision September 26 2000

This study was supported by Grant \#7.0058.94, "Levenslijn", Fund for Scientific Research in Flanders. Ful support was given by the Provincial Institute of Hygiene.

\section{Areas}

This study was carried out in Belgium, in the centre of Antwerp (urban) and in 13 municipalities at the southern border of the city (suburban). The urban area consisted of the busy, densely populated, historical centre of Antwerp; the suburban area included 13 municipalities with residential and rural features. The centres of these 13 municipalities were located at only a mean distance of $9 \mathrm{~km}$ from the city centre. A more detailed description of these areas has been given previously [5].

\section{Study population}

In children, the methods of the ISAAC [7] were applied to two study groups aged 5-8 yrs and 12-15 yrs, respectively. The ISAAC questionnaire was distributed in 1995 to the parents of all children from the first and second grades of all primary schools (mostly 6-7 yrs of age) within the urban and suburban areas. In the same areas in 1995 and 1996, one third of all secondary schools were also randomly selected for participation. All children in the second grade of these schools (mostly aged 13-14 yrs) were asked to fill 
in the ISAAC questionnaire themselves during one school hour [8].

In 1996, two sample groups of 3,000 adults, respectively aged 20-44 (younger) and 45-75 yrs (older), were randomly selected from the registers of the same municipalities in each of the two areas, for screening for respiratory symptoms. Prevalence rates of respiratory symptoms and asthma in the subjects aged 20 44 yrs were compared to those previously obtained in the comparable survey of 1991-1992 [1, 6].

\section{Questionnaires}

In the two children study groups, the translated ISAAC screening questionnaires were used to assess occurrence rates of respiratory, nasal and skin symptoms. The questionnaires were extended to include some further questions on respiratory symptoms and on prominent risk factors.

To screen for respiratory symptoms in the two adult study groups, the authors used the ECRHS postal questionnaire [9]. It was extended to include questions about potential risk factors, and in the oldest study group, questions on symptoms suggestive of chronic obstructive pulmonary disease (COPD). Subjects who did not respond to the first questionnaire were sent two reminders.

\section{Nonresponse}

In all groups information on nonresponders was collected to enable the study of nonresponse bias. For the nonresponding children aged 13-14 yrs, teachers or close friends were asked about respiratory symptoms. In all other study groups a random sample of the (initial) nonresponders was contacted again by phone or through a home visit. In order to investigate the potential impact of selection bias the authors examined the effect of a different occurrence rate for the total population using the assumption that the occurrence in nonresponders would be half the occurrence in the responders.

\section{Analysis}

Occurrence rates were calculated by dividing the number of positive answers by the total number of respondents to the particular question, and multiplying by 100 ; numbers in the tables refer to the whole study group. All data were analysed separately for males and females to exclude any possible influence of sexrelated differences. Occurrence rates of wheezing and asthma were also determined in (a sample of) the nonresponders.

Adjusted associations between respiratory symptoms and area of residence within the 4 study groups were calculated, using a logistic regression model, and expressed as odds ratios (95\% confidence interval). In the 5-8 yr old children associations were adjusted for age, parental asthma, parental hay fever, parental recurrent wheezy bronchitis and parental eczema; in the $12-15 \mathrm{yr}$ olds, associations were adjusted for age, parental asthma, parental hay fever and personal smoking. In younger and older adults adjustment was made for age, asthma in siblings, personal smoking (ex-, light-, heavy-smoker, with "never" as reference category) and the number of reminders received before completing the questionnaire.

All subjects were further divided into the following age groups: $5-8 ; 12-15 ; 20-29 ; 30-39 ; 40-49 ; 50-59$; 60-69 and 70-75 yrs. Crude associations between area of residence and "wheezing in the last 12 months" were calculated within these age groups to improve insight into the age distribution of the area differences.

The statistical package Statistica (StatSoft Inc, Tulsa, USA) was used for all analyses, and logistic regression analysis was performed in EGRET (Cytel, Seattle, USA).

The study was approved by the Ethical Committee of the University of Antwerp.

\section{Results}

As shown in tables 1 and 2, for males and females, respectively, there were no consistent differences in occurrence rates of respiratory symptoms and asthma between the urban and suburban areas in the 5-8 and $12-15 \mathrm{yr}$ old children, whereas these rates were consistently higher in urban Antwerp for both younger (20-44 yrs) and older adults (45-75 yrs). Boys aged 5-8 yrs had higher prevalence rates for respiratory symptoms than girls, but in $12-15$ and $20-44$ yr old subjects, sex differences were smaller, or even inverse, except for the occurrence of asthma. In the older study group, males again more often reported respiratory symptoms and asthma.

Comparisons of prevalence rates for respiratory symptoms and asthma in 20-44 yr old adults in both the 1991-1992 and 1996 surveys (fig. 1) shows the urban-suburban differences to be of similar magnitude and significance $(\mathrm{p}<0.05)$, except for asthma in the last 12 months, in 1996. P-values for the differences between 1991-1992 and 1996 were all below 0.05, except for nocturnal dyspnoea and nocturnal cough in urban Antwerp, and asthma in the last 12 months, where the $\mathrm{p}$-value $>0.1$. Furthermore, reported prevalence rates were on average $32 \%$ higher in 1996 than in 1991-92, for both areas.

The response rate in the group aged 5-8 yrs was $86 \%$, in the $12-15$ yr olds group it reached $97 \%$. In the sample of nonresponders in these study groups, occurrence rates were only slightly lower than in responders. For both the 20-44 and 45-75 yr old study groups, the response rates were markedly lower, $57 \%$. In initial nonresponders, occurrence rates for wheezing and "ever having had asthma" in the 20-44 yr study group were lower than in responders (table 3 ), but they were still higher in the urban area, and differences with the suburban area were of a similar magnitude. In the 45-75 yr group, rates of wheezing and "ever having had asthma" in initial nonresponders were quite similar to those in responders (table 3). The increase in the occurrence of respiratory symptoms in adults observed between 1991-1992 and 1996 was not sensitive to various assumptions regarding symptoms in nonresponders. Table 4 presents the estimated 
Table 1. - Occurrence rates (\%) of respiratory symptoms and asthma in urban (UA) and suburban (SA) Antwerp, in all study groups, males

\begin{tabular}{|c|c|c|c|c|c|c|c|c|}
\hline \multirow{2}{*}{ Symptoms } & \multicolumn{2}{|c|}{$5-8$ yrs } & \multicolumn{2}{|c|}{$12-15$ yrs } & \multicolumn{2}{|c|}{$20-44$ yrs } & \multicolumn{2}{|c|}{$45-75$ yrs } \\
\hline & UA & SA & UA & SA & UA & SA & UA & SA \\
\hline Subjects $n$ & 1049 & 1712 & 381 & 685 & 690 & 892 & 735 & 908 \\
\hline Wheeze ever & $19.8^{*}$ & 23.7 & 18.1 & 19.1 & & & & \\
\hline Wheeze last 12 months & 9.13 & 9.18 & 12.3 & 10.7 & $27.0 *$ & 18.2 & $25.3 *$ & 18.9 \\
\hline Wheeze with dyspnoea & & & & & $14.1 *$ & 8.39 & $14.4^{*}$ & 10.1 \\
\hline Wheeze without a cold & $8.36^{*}$ & 11.0 & 15.8 & 13.2 & $18.9^{*}$ & 12.0 & $17.6^{*}$ & 13.6 \\
\hline Exercise wheeze & 4.73 & 4.58 & 13.2 & 13.2 & & & & \\
\hline Nocturnal wheeze $\mathrm{e}^{\#}$ & 4.41 & 4.56 & 3.67 & 2.20 & & & & \\
\hline Nocturnal tightness $^{\#}$ & & & & & $13.2^{*}$ & 9.41 & $14.2^{*}$ & 8.41 \\
\hline Nocturnal dyspnoea ${ }^{\#}$ & & & & & 7.51 & 5.34 & 8.91 & 7.68 \\
\hline Nocturnal cough & & & & & $24.8^{*}$ & 18.6 & $24.0^{*}$ & 18.1 \\
\hline Dry nocturnal cough no cold $\#$ & 16.5 & 16.9 & 18.5 & 22.4 & & & & \\
\hline Coughing 4 weeks & 6.40 & 5.53 & 8.19 & 8.79 & & & & \\
\hline Phlegm 4 weeks ${ }^{\#}$ & $4.22 *$ & 2.62 & 7.93 & 8.19 & & & & \\
\hline Asthma ever & 5.76 & 5.09 & 8.18 & 8.81 & 8.17 & 6.63 & 6.64 & 5.04 \\
\hline Asthma last 12 months $^{+}$ & 2.98 & 2.01 & 4.76 & 4.40 & 2.87 & 2.66 & 3.60 & 2.37 \\
\hline Asthma medication ever & $13.7^{*}$ & 17.0 & 10.5 & 12.3 & & & & \\
\hline Asthma medication at moment & 3.68 & 5.05 & 4.00 & 4.32 & 4.59 & 4.09 & 8.91 & 6.68 \\
\hline Three months daily cough ${ }^{\S}$ & & & & & & & $20.3^{*}$ & 14.0 \\
\hline Three months daily phlegm ${ }^{\S}$ & & & & & & & $19.0^{*}$ & 12.9 \\
\hline Emphysema $^{f}$ & & & & & & & $10.1^{*}$ & 5.86 \\
\hline
\end{tabular}

\#: in the last 12 months; " : in the 5-8 and 12-15 yr study groups this referred to "ever in the past"; in the 20-44 and 45-75 yr study groups this referred to "the last 12 months"; ${ }^{+}$: in the 20-44 and 45-75 yr study groups: "asthma attacks in the last 12 months"; ${ }^{\S}$ : in the last $2 \mathrm{yrs}^{f}$ : chronic bronchitis or emphysema; *: $\mathrm{p} \leqslant 0.05$ UA versus SA.

occurrence rates for the total population, based on the assumption that the occurrence in nonresponders would be half the rate of the responders.

Adjustment for the recorded potential risk factors hardly changed the associations between area and symptoms in the 5-8 and 12-15 yr old subjects (not shown). In the 20-44 and 45-75 yr study groups, adjustment weakened most associations (table 5), but subjects living in urban Antwerp still had a higher risk for the occurrence of most respiratory symptoms and asthma. In the 20-44 yr age group, most associations were slightly stronger in females than in males, while in the older adults there was an inverse trend (i.e. stronger in males than females).

Crude associations between area of residence and wheezing in the last 12 months, within groups of

Table 2. - Occurrence rates (\%) of respiratory symptoms and asthma in urban (UA) and suburban (SA) Antwerp, in all study groups, females

\begin{tabular}{|c|c|c|c|c|c|c|c|c|}
\hline \multirow{2}{*}{ Symptoms } & \multicolumn{2}{|c|}{$5-8$ yrs } & \multicolumn{2}{|c|}{$12-15 \mathrm{yrs}$} & \multicolumn{2}{|c|}{$20-44$ yrs } & \multicolumn{2}{|c|}{$45-75$ yrs } \\
\hline & UA & SA & UA & SA & UA & SA & UA & SA \\
\hline Subjects n & 1201 & 1667 & 419 & 495 & 816 & 979 & 716 & 954 \\
\hline Wheeze ever & 14.3 & 16.6 & 18.6 & 18.8 & & & & \\
\hline Wheeze last 12 months & 4.85 & 6.17 & 12.2 & 11.5 & $23.8^{*}$ & 16.2 & $18.6^{*}$ & 14.3 \\
\hline Wheeze with dyspnoea\# & & & & & $13.5^{*}$ & 8.52 & $12.2 *$ & 8.68 \\
\hline Wheeze without a cold & 6.03 & 7.08 & 12.7 & 12.1 & $16.0 *$ & 9.44 & $12.1 *$ & 8.57 \\
\hline Exercise wheeze & 3.09 & 2.72 & 14.3 & 17.0 & & & & \\
\hline Nocturnal wheeze & 2.09 & 2.46 & 3.37 & 3.46 & & & & \\
\hline Nocturnal tightness & & & & & $13.2^{*}$ & 8.62 & $12.3 *$ & 7.65 \\
\hline Nocturnal dyspnoea ${ }^{\#}$ & & & & & $8.49 *$ & 4.64 & $9.49 *$ & 5.32 \\
\hline Nocturnal cough & & & & & 33.5 & 29.4 & $24.8 *$ & 20.9 \\
\hline Dry nocturnal cough no cold & 13.6 & 14.2 & 26.3 & 24.9 & & & & \\
\hline Coughing 4 weeks & 5.04 & 6.18 & 9.47 & 12.7 & & & & \\
\hline Phlegm 4 weeks $^{\#}$ & 3.42 & 2.39 & 8.59 & 8.62 & & & & \\
\hline Asthma ever & $4.21 *$ & 2.42 & 6.67 & 5.70 & 6.17 & 4.69 & 5.67 & 4.27 \\
\hline Asthma last 12 months $^{+}$ & 1.43 & 1.27 & 4.51 & 2.64 & $3.70 *$ & 1.41 & $3.53 *$ & 1.63 \\
\hline Asthma medication ever & 9.32 & 10.9 & 9.07 & 6.03 & & & & \\
\hline Asthma medication at moment & $1.96^{*}$ & 3.19 & 2.84 & 1.88 & $4.30^{*}$ & 2.61 & $7.69 *$ & 5.38 \\
\hline Three months daily cough ${ }^{\S}$ & & & & & & & $16.5^{*}$ & 8.99 \\
\hline Three months daily phlegm ${ }^{\S}$ & & & & & & & $12.6^{*}$ & 8.35 \\
\hline Emphysema $^{f}$ & & & & & & & $7.63^{*}$ & 3.99 \\
\hline
\end{tabular}

\#: in the last 12 months; ${ }^{\circ}$ : in the 5-8 and 12-15 yr study groups this referred to "ever in the past"; in the 20-44 and 45-75 yr study groups this referred to "the last 12 months"; ${ }^{+}:$in the $20-44$ and $45-75$ yr study groups: "asthma attacks in the last 12 months"; : in the last 2 yrs; ${ }^{f}$ : chronic bronchitis or emphysema; *: $\mathrm{p} \leqslant 0.05$ UA versus SA. 


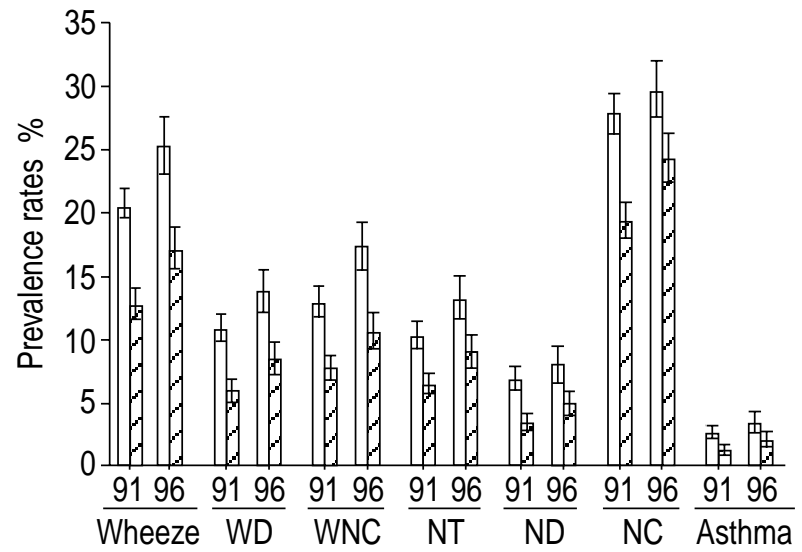

Fig. 1. - Prevalence rates (95\% condidence intervals) of respiratory symptoms and asthma in the last 12 months in 20-44 yr old subjects, living in urban $(\square)$ and suburban $(\mathbb{Z})$ Antwerp, as reported in two surveys: one in 1991-1992 and one in 1996. WD: wheezing with dyspnoea; WNC: wheezing without a cold; NT: nocturnal tightness; ND: nocturnal dyspnoea; NC: nocturnal coughing; 91: 1991-2 study; 96: 1996 study.

increasing age, are shown in figure 2 for males and females separately. The magnitude of the associations tended to be slightly larger in adults than in children.

\section{Discussion}

The main finding of the study is the higher occurrence of asthma-related symptoms in the urban compared to the suburban area, in both younger (20-44 yrs) and older (45-75 yrs) adults, whereas such consistent differences were not found in 5-8 and 12$15 \mathrm{yr}$ old children. Even after adjustment for recorded risk factors, younger and older adults living in urban Antwerp still had a higher risk for most respiratory symptoms. The 1996 survey in $20-44 \mathrm{yr}$ old subjects confirmed the authors' previous findings [1, 5, 6]; not only were prevalence rates again higher in the urban area, but the differences between the areas were also of a similar magnitude and all recorded rates had on average increased by $32 \%$, in both areas, between 1991 and 1996, a time-related increase similar to that found by others $[10,11]$.

Response rates, a critical issue in population-based surveys, were high in the two child groups and there were only minor differences in occurrence of symptoms between responders and initial nonresponders. In both older age groups, response rates were only $57 \%$ in 1996 , but differences between areas were the same for responders and nonresponders, both in direction and magnitude, although most occurrence rates tended to be lower in the latter. Moreover, adjustment for the number of reminders hardly influenced the differences in symptom-reporting between the areas. The authors are therefore confident that, with respect to the area differences, response bias did not affect the results. Response rates in the 20-44 yr old adults in 1991-1992 were higher than in 1996, 75\% versus $57 \%$ respectively. Sensitivity analyses, based on different assumptions of prevalence rates of nonresponders, showed that the lower response rate in 1996 may only partly explain the higher prevalence rates found in 1996.

This cross-sectional study retrospectively collected data on exposure and life-time occurrence of symptoms. Differences in occurrence rates between the different age groups could therefore result from exposures to different risk factors at different times (cohort effect). In the youngest group (5-8 yrs) information was given by their parents, while in all other age groups symptoms were self-reported. The exact phrasing of some questions also slightly differed between the childrens' and adults' questionnaires, especially between "wheezing apart from a cold" and "asthma in the last 12 months". However, the urbansuburban comparison within age groups is not thought to be influenced by cohort effects, nor by the self- versus parental-reporting, nor by slightly different phrasing of questions.

To explore any possible bias resulting from slight differences in methods used, associations between area and respiratory symptoms were assessed in the different age groups within the study groups. A trend towards increased odds ratio was found for the associations between area and wheezing in the last 12 months, in adults, in comparison with children, in both males and females. This suggests that the area effects differ with age, and that they are consistently found in the agegroups of younger and older adults, thus supporting the validity of the present findings.

A gradient in asthma-related symptoms between urban and rural areas has already been reported in several studies in Africa [12,13] and in comparisons in USA "inner cities" [14]. However, a gradient in the occurrence of respiratory symptoms between neighbouring areas, only a few kilometres apart, with a homogeneous, and in the present case Flemish, population has not been reported before. Differences in genetic background cannot be expected to be responsible for the observed area differences; neither is it

Table 3. - Assesment of the effect of nonresponse

\begin{tabular}{|c|c|c|c|c|c|c|c|c|}
\hline \multirow{3}{*}{ Symptoms } & \multicolumn{4}{|c|}{$20-24$ yrs } & \multicolumn{4}{|c|}{$45-75$ yrs } \\
\hline & \multicolumn{2}{|c|}{ Responders } & \multicolumn{2}{|c|}{ Nonresponders } & \multicolumn{2}{|c|}{ Responders } & \multicolumn{2}{|c|}{ Nonresponders } \\
\hline & UA & SA & UA & SA & UA & SA & UA & SA \\
\hline Subjects n & 1506 & 1871 & 71 & 71 & 1451 & 1862 & 89 & 79 \\
\hline Wheeze last 12 months & 25.2 & 17.2 & 14.3 & 7.0 & 22.0 & 16.5 & 21.3 & 15.2 \\
\hline Asthma ever & 7.1 & 5.6 & 4.3 & 4.2 & 6.2 & 4.6 & 7.9 & 5.1 \\
\hline
\end{tabular}

Occurrence rates $(\%)$ of respiratory symptoms in responders and nonresponders in adults in urban (UA) and suburban (SA) Antwerp. 
Table 4. - Occurrence rates of respiratory symptoms in the last 12 months for the two studies

\begin{tabular}{|c|c|c|c|c|c|c|c|c|}
\hline & \multicolumn{4}{|c|}{ 1991-1992 (response: 75\%) } & \multicolumn{4}{|c|}{1996 (response: 57\%) } \\
\hline & \multicolumn{2}{|c|}{ Response } & \multicolumn{2}{|c|}{ Estimation in total population } & \multicolumn{2}{|c|}{ Response } & \multicolumn{2}{|c|}{ Estimation in total population } \\
\hline & SA & UA & SA & UA & SA & UA & SA & UA \\
\hline Subjects $n$ & 3066 & 2958 & 4088 & 3944 & 1901 & 1531 & 3335 & 2686 \\
\hline Wheeze & 12.8 & 20.4 & 11.2 & 17.8 & 17.2 & 25.2 & 13.3 & 19.6 \\
\hline Wheeze without a cold & 7.71 & 12.9 & 6.73 & 11.2 & 10.7 & 17.3 & 8.25 & 13.4 \\
\hline Nocturnal tightness & 6.46 & 10.3 & 5.65 & 9.03 & 9.00 & 13.2 & 7.08 & 10.3 \\
\hline Nocturnal dyspnoea & 3.46 & 6.87 & 3.03 & 6.01 & 4.97 & 8.05 & 3.90 & 6.29 \\
\hline Asthma attacks & 1.27 & 2.61 & 1.10 & 2.28 & 2.00 & 3.32 & 1.56 & 2.61 \\
\hline
\end{tabular}

Occurrence rates (\%) of symptoms in the last 12 months for 1991-1992 and 1996 in responders and the total population, based on the assumption that the occurrence rates in nonresponders would be half the rate of the responders. SA: suburban Antwerp; UA: urban Antwerp.

expected that these would be greatly confounded by differences in personal risk factors. Nonetheless, a number of determinants listed by BECKLAKE and ERNST [15] were explored for possible confounding.

Age, smoking habits, asthma in siblings and response, partly explained the differences between urban and suburban Antwerp, but even after adjustment for these factors, adults living in urban Antwerp still had a higher risk for most respiratory symptoms than those in the suburban area. For estimation of social economic status (SES), the authors had to use as a proxy "age at completing full time education" in the 20-44 yr old study group. A confounding effect of SES seems unlikely since $35 \%$ and $37 \%$ of subjects in the urban and suburban areas, respectively, completed education before or at age 18. In the same age group in 1991-1992, other personal risk factors, such as "having had a severe respiratory infection before the age of 5" and "smoking of the mother during pregnancy or childhood" as well as some housing factors ("an open fire for heating" and "moulds in the last 12 months") failed to explain area differences in respiratory symptoms [5]. No evidence could be found for a confounding effect of family size or having older brothers or sisters. Information regarding dietary risk factors [16], such as fruit, fish and salt intake, was only available in the 5-8 and 12-15 yr old children, but no relevant differences in such habits were recorded between the urban and suburban areas.

In the 1991-1992 surveys, house dust mite (HDM) allergy was found to explain most of the urban- suburban differences in childhood asthma in young adults, but not the difference in recent occurrence of asthma symptoms [5]. In the recent surveys, skin allergy testing was only performed in a subgroup of the 5-8 $\mathrm{yr}$ old children, and higher prevalence rates of HDM allergy were only found in boys of the urban area [17]; this allergy could precede an increased occurrence of respiratory symptoms later in life. This also weighs against a cohort effect between the different study groups.

Area differences in occurrence of asthma-related symptoms probably reflect differences in life-time exposure to the environment. Area of residence was the proxy variable used for assessing this exposure. However, this could have induced misclassification bias, since the official residence is not necessarily the place where subjects spend most of their time. Indeed, approximately one third of the subjects' time is spent at work or at school. Migration of the subjects may be another obvious cause of misclassification with respect to life-time exposure. However, in repeated modelling of these effects, such misclassification, whether differential or nondifferential, was more likely to attenuate than increase observed area differences.

Although the area differences in respiratory symptoms and asthma in adults seem to be real, it is still not clear which causative factors linked to the urban area could be responsible for an "urban asthma" effect. A progressive effect of higher levels of exposure to air pollution from traffic in the urban area would be a

Table 5. - Adjusted associations* (odds ratiourban-Suburban, (95\% confidence interval)) between symptoms and area of residence in the oldest study groups

\begin{tabular}{|c|c|c|c|c|}
\hline \multirow[b]{2}{*}{ Symptoms } & \multicolumn{2}{|c|}{$20-44$ yrs } & \multicolumn{2}{|c|}{$45-75$ yrs } \\
\hline & Males & Females & Males & Females \\
\hline Wheeze $^{\#}$ & $1.29(1.00-1.68)$ & $1.17(0.90-1.50)$ & $1.22(0.95-1.58)$ & $1.03(0.77-1.38)$ \\
\hline Wheeze with dyspnoea ${ }^{\#}$ & $1.46(1.04-2.05)$ & $1.31(0.95-1.81)$ & $1.29(0.94-1.77)$ & $1.05(0.74-1.49)$ \\
\hline Wheeze without a cold $\#$ & $1.26(0.93-1.70)$ & $1.35(0.99-1.82)$ & $1.21(0.90-1.62)$ & $1.05(0.74-1.49)$ \\
\hline Nocturnal tightness $\#$ & $1.20(0.86-1.67)$ & $1.46(1.07-1.99)$ & $1.62(1.17-2.24)$ & $1.49(1.06-2.10)$ \\
\hline Nocturnal dyspnoea $^{\#}$ & $1.17(0.76-1.81)$ & $1.91(1.28-2.84)$ & $1.03(0.71-1.49)$ & $1.56(1.05-2.33)$ \\
\hline Nocturnal cough $\#$ & $1.15(0.89-1.49)$ & $1.09(0.88-1.33)$ & $1.31(1.02-1.68)$ & $1.05(0.82-1.34)$ \\
\hline Asthma ever & $1.24(0.82-1.86)$ & $1.15(0.74-1.79)$ & $1.37(0.88-2.13)$ & $1.21(0.75-1.95)$ \\
\hline Asthma attacks in last 12 months & $1.05(0.55-2.01)$ & $2.31(1.19-4.49)$ & $1.64(0.87-3.10)$ & $1.46(0.74-2.88)$ \\
\hline Asthma medication at moment & $0.96(0.57-1.62)$ & $1.45(0.84-2.49)$ & $1.26(0.86-1.86)$ & $1.12(0.73-1.70)$ \\
\hline Three months daily cough & & & $1.39(1.05-1.83)$ & $1.74(1.27-2.39)$ \\
\hline Three months daily phlegm & & & $1.42(1.07-1.89)$ & $1.24(0.88-1.75)$ \\
\hline Emphysema & & & $1.59(1.08-2.35)$ & $1.29(0.81-2.04)$ \\
\hline
\end{tabular}

*: adjusted for age, asthma in siblings, personal smoking and number of reminders; ${ }^{*}$ : in the last 12 months; ": in the last 2 yrs. 


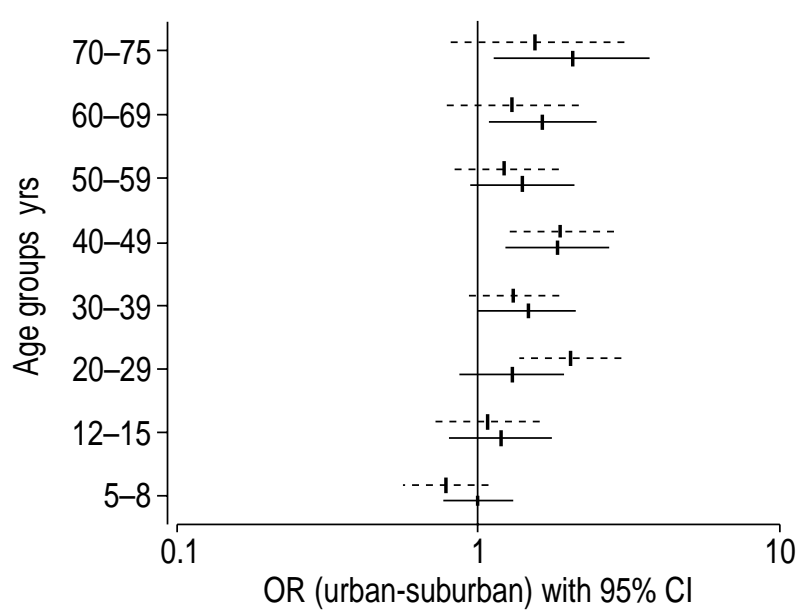

Fig. 2. - Associations (expressed as odds ratios (OR's) on a logarithmic scale) for males (-) and females (- - -) between area of residence and wheezing in the last 12 months in several age groups. CI: confidence interval.

cause to consider. Exposures to gaseous pollutants and ultrafine particles in diesel exhaust fumes have been associated with atopy and asthmatic airway inflammation [18-20], even though their effects on symptoms are still controversial [21]. Except for diesel vehicles constituting approximately $50 \%$ of all motor vehicles in Belgium and the observation that traffic congestion is high in our city centres, there are at present, no further data associating our area-differences with exposure to traffic-related air pollution.

In conclusion, this systematic comparison of asthma occurrence in people whose ages span 70 yrs, carried out in an urban and an adjacent suburban area of a medium size cosmopolitan city, suggests a progressive effect of long-term exposure to the urban environment. A number of factors that have been associated with "urban asthma" in other studies cannot explain this effect in the present populations. Follow-up studies, in an advanced planning stage, of the cohort that participated in the European Community Respiratory Health Survey and the International Study of Asthma and Allergies in Childhood could provide more support for a hypothesis of a long-term "urban asthma" effect.

Acknowledgements. The authors gratefully acknowledge the invaluable technical help of L. Claus, L. Thijs, C. Van den Heuvel, R. Claes, R Goosens, G Meyssen, G. Van den Vijver, M. Willemen and J. Geldhof.

\section{References}

1. European Community Respiratory Health Survey. Variations in the prevalence of respiratory symptoms, self-reported asthma attacks, and use of asthma medication in the European Community Respiratory Health Survey (ECRHS). Eur Respir J 1996; 9: 687-695.

2. International Study of Asthma and Allergies in Childhood (ISAAC) Steering Committee. Worldwide variation in prevalence of symptoms of asthma, allergic rhino conjunctivitis, and atopic eczema: ISAAC. Lancet 1998; 351: 1225-1232.
3. von Mutius E, Martinez FD, Fritzsch C, Nicolai T, Roell G, Thiemann HH. Prevalence of asthma and atopy in two areas of West and East Germany. Am J Respir Crit Care Med 1994; 149: 358-364.

4. Nowak D, Heinrich J, Jorres R, et al. Prevalence of respiratory symptoms, bronchial hyperresponsiveness and atopy among adults: west and east Germany. Eur Respir J 1996; 9: 2541-2552.

5. Wieringa MH, Weyler JJ, Van Bastelaer FJ, Nelen VJ, Van Sprundel MP, Vermeire PA. Higher asthma occurrence in an urban than a suburban area: role of house dust mite skin allergy. Eur Respir J 1997; 10: $1460-1466$.

6. Wieringa MH, Weyler JJ, Nelen VJ, et al. Prevalence of respiratory symptoms: marked differences within a small geographical area. Int J Epidemiol 1998; 27: 630635 .

7. Asher MI, Keil U, Anderson HR, et al. International Study of Asthma and Allergies in Childhood (ISAAC): rationale and methods. Eur Respir J 1995; 8: 483-491.

8. Wieringa MH, Weyler JJ, Van Bever HP, Nelen VJ, Vermeire PA. Gender differences in respiratory, nasal and skin symptoms: 6-7 versus 13-14-year-old children. Acta Paediatr 1999; 88: 147-149.

9. Burney PG, Luczynska C, Chinn S, Jarvis D. The European Community Respiratory Health Survey. Eur Respir J 1994; 7: 954-960.

10. Burr ML, Butland BK, King S, Vaughan-Williams E. Changes in asthma prevalence: two surveys 15 years apart. Arch Dis Child 1989; 64: 1452-1456.

11. Peat JK, Haby M, Spijker J, Berry G, Woolcock AJ. Prevalence of asthma in adults in Busselton, Western Australia. BMJ 1992; 305: 1326-1329.

12. Becklake MR. International union against tuberculosis and lung disease (IUATLD): initiatives in non-tuberculous lung disease. Tuber Lung Dis 1995; 76: 493-504.

13. Van Niekerk CH, Weinberg EG, Shore SC, Heese HV, Van Schalkwyk J. Prevalence of asthma: a comparative study of urban and rural Xhosa children. Clin Allergy 1979; 9: 319-324.

14. Weiss KB, Wagener DK. Asthma surveillance in the United States. A review of current trends and knowledge gaps. Chest 1990; 98: 179S-184S.

15. Becklake MR, Ernst P. Environmental factors. Lancet 1997; 350 Suppl 2: 10-13.

16. Peat JK. Prevention of asthma. Eur Respir J 1996; 9: 1545-1555.

17. Wieringa MH, Weyler JJ, Van Bever HP, Nelen VJ, Van Sprundel MP, Vermeire PA. Comparison of gender differences in skin allergy prick testing in children and adults living in urban and suburban areas. Eur Respir J 1997; 10: Suppl. 25, 144s.

18. Blomberg A. Airway inflammatory and antioxidant responses to oxidative and particulate air pollutants - experimental exposure studies in humans. Clin Exp Allergy 2000; 30: 310-317.

19. Kramer U, Koch T, Ranft U, Ring J, Behrendt H. Traffic-related air pollution is associated with atopy in children living in urban areas. Epidemiology 2000; 11: 64-70.

20. Salvi SS, Frew A, Holgate S. Is diesel exhaust a cause for increasing allergies? Clin Exp Allergy 1999; 29: 4-8.

21. Roemer W, Hoek G, Brunekreef B. Pollution effects on asthmatic children in Europe, the PEACE study. Clin Exp Allergy 2000; 30: 1067-1075. 